\title{
CONSIDERATIONS ON DOP (DEPTH OF PENETRATION) TEST FOR EVALUATION OF CERAMICS MATERIALS USED IN BALLISTIC PROTECTION
}

\author{
POPA Ioan-Dan, Faculty of Engineering, Lucian Blaga University, Sibiu, Romania, \\ paragon1971@gmail.com \\ DOBRIŢA Florin, Faculty of Engineering, Lucian Blaga University, Sibiu, Romania, \\ dobritaflorin@gmail.com
}

\begin{abstract}
Tremendous amount of funds and other resorces were invested in studying the response of ceramic materials under ballistic impact, the main goal being to find a way to increase the protection of soldiers and the vehicles used in the modern battlespace. Using of ceramic materials especially carbon based (carbides), nitrogen based (nitrides) and oxygen based (oxides) ceramics in order to increase the protection level of ballistic equipment could be, sometimes, a big challenge when trying to use the proper test in order to evaluate and compare their performances. The role of the tests is to provide a better understanding of their response in different situations and, as a consequence, to make them more efficient as armour components through future improvements. The paper presents shortly the main tests which are used and eventually standardised for evaluating the ballistic behaviour of the ceramics and other armour components, with a special focus to DOP (Depth of Penetration) Tests.
\end{abstract}

Keywords: ceramic, ballistic protection, DOP

\section{Introduction}

The term ceramics it is explained as being derived from the Greek word "keramos" which means "burn stuff". In his book, "A concise introduction to ceramics", Philips [1] emphasises the fact that today ceramics are more popular than ever before, due to the fact that they are often harder, lighter, stiffer and more resistant when compared to metals. Due to the relatively low cost and abundance of their raw materials, ceramics have experienced an increase in their use for various applications in many fields. This variety of applications requires customization of the ceramic material; therefore new formulations are tested and accepted into production on regular basis. The armour application for ceramic materials is a relatively new development. Only in about the last 30 years has this type of armour proved its efficiency in large scale deployments. Its main advantage is its reduced mass; the ceramic armour has a lower areal mass compared to the steel armour needed to defeat the same kinetic energy based threat.

There are three main groups of ceramics widely employed in armour manufacturing as well as other more common applications. These groups are carbon based (carbides), nitrogen based (nitrides) and oxygen based (oxides) ceramics. The impact of a typical tri-layer structure is presented in Figure 1, the ceramic material being in the middle.
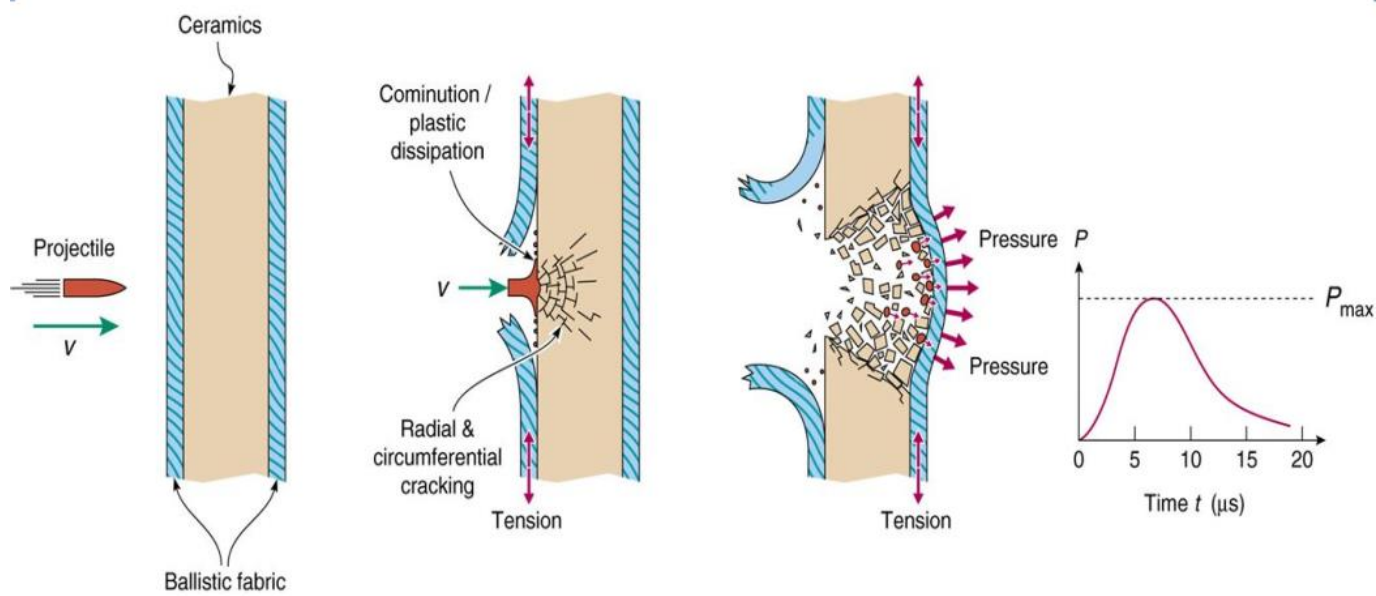

Figure 1: The impact of a typical tri-layer structure with ceramic in the middle Source: (http://www.virginia.edu/ms/research/wadley/ballistic-impact.html) 


\section{ACTA UIVERSITATIS CIBINIENSIS - TECHNICAL SERIES}

Vol. LXIX 2017

In order to compare different kinds of ceramic materials and to have the real image of the ballistic protection properties, it is necessary to perform some tests which will be presented in the next paragraph.

\section{Ballistic tests used to evaluate ceramics}

Tremendous amount of funds and other resorces were invested in studying the response of ceramic materials under ballistic impact, the main goal being to find a way to increase the protection of soldiers and the vehicles used in the modern battlespace. During the last several years, a series of tests were used and eventually standardised for evaluating the ballistic behaviour of the ceramics and other armour components. For example, the test preferred during the final stages of the armour development is the Ballistic Limit Velocity (V50) in which the final armour is impacted with a standard projectile at different velocities until the limit velocity is found $(50 \%$ of the projectiles at that velocity did not penetrate the armour). By varying the thickness of the ceramic or other parameters, a ballistic limit curve can be obtained for that particular projectile-armour pair, but testing costs are high. In order to reduce the high costs, some tests in the early stages of a ceramic based armour development are required. Normandia and Gooch [2] in one of their published article, summarised these tests in Table 1. Most of the tests presented in this table, such as DWE, DPT, FTG, BAD and TAD are pertaining to entire armour systems rather than individual elements.

Table 1: Ceramic Material Evaluation Summary of Ballistic Test Methods

\begin{tabular}{|c|c|c|}
\hline Test & Test Type & Information obtained \\
\hline NDP & $\begin{array}{l}\text { Non-Deforming } \\
\text { Penetration }\end{array}$ & $\begin{array}{l}\text { Typically used for soft metals and hard targets, this } \\
\text { applies for concrete, limestone and other geological } \\
\text { materials. Various researchers attempt to isolate target } \\
\text { resistance in this penetration mode. }\end{array}$ \\
\hline PEN & $\begin{array}{l}\text { Penetration Depth Direct } \\
\text { or Reverse Impact }\end{array}$ & $\begin{array}{l}\text { Penetration-velocity curves, penetration resistance, } \\
\text { penetration rate, penetrator consumption rate. }\end{array}$ \\
\hline DOP & $\begin{array}{l}\text { Modified Depth-of- } \\
\text { Penetration }\end{array}$ & $\begin{array}{l}\text { Relevant for determination of performance goals as a } \\
\text { function of ceramic thickness - similar to TAD, but in a } \\
\text { semi-infinite configuration. }\end{array}$ \\
\hline DWE & Dwell Tests & Total interface defeat conditions. \\
\hline DPT & Dwell / Penetration Transition & $\begin{array}{l}\text { Velocity defines a load that is characteristic of a failure } \\
\text { shear strength of the ceramic, or of a transition strain. }\end{array}$ \\
\hline FTG & Fixed Target Geometry & $\begin{array}{l}\text { Generic material comparison experiment in armor-like } \\
\text { configurations, particularly at obliquity. }\end{array}$ \\
\hline TCA & Composite Armour & Configuration to minimize the use of damaged material. \\
\hline VBL & $\begin{array}{l}\text { Ballistic Limit Velocity (V50) or } \\
\text { Residual Data }\end{array}$ & $\begin{array}{l}\text { Typical requirement for acceptable armor, individual tests } \\
\text { measure residual penetrator characteristics. }\end{array}$ \\
\hline BAD & Behind Armour Debris & $\begin{array}{l}\text { Used to measure the lethality of the penetrator or the } \\
\text { vulnerability of the target to an overmatched threat. Data } \\
\text { quantification utilized in lethality assessment tools. }\end{array}$ \\
\hline TAD & $\begin{array}{l}\text { Target Areal Density } \\
\text { Performance Mops }\end{array}$ & $\begin{array}{l}\text { Helps determine near-optimal armor configurations } \\
\text { Theories permit extrapolation to different threats. }\end{array}$ \\
\hline
\end{tabular}

Source: Normandia and Gooch [2]

\section{DOP (Depth of Penetration) Test}

There is no doubt that one of the most preferred tests in the early stages of armour manufacturing is the Depth of Penetration (DOP) in which the ceramic or other armour materials are backed by a semi- 
infinite material. The impacting projectile is designed to overmatch the ceramic material and its residual forward momentum is to be stopped in the semi-infinite backing. A DOP value is obtained by measuring the depth at which the projectile embeded itself in the backing material with and without protection. By comparing the penetration of a projectile into a ceramic protected target and an unprotected target, the ceramic's ballistic performance may be determined.

According to Darin Ray [3], another way to compare this ballistic data is to measure the initial diameter of the hole in the backing material. As an alternative to measuring the depth in the backing, especially when X-ray or other expensive equipment might be needed, he considers that when the depth of penetration is shallow, the harder ceramic has spread the bullet fragments and ceramic debris that penetrates into the backing compared to the smaller initial diameter when a softer ceramic is used.

It is generally agreed that the DOP testing doesn't offer the final answer on formulating the best armour design; it is still an excellent screening tool for the possible ceramic materials, in which a large amount of data can be collected quickly and relatively inexpensively from a minimal amount of samples. The ranking obtained in the DOP by the tested materials might not be entirely mirrored in the final design; however Robertson [4] considers that materials failing to impress in terms of performance against the particular test projectile in DOP regime will most of the time perform poorly in the practical armour system.

The data collected during the DOP tests does not usually include stress, strain or damage accumulation to be used in future simulations. However, the DOP testing is a practical and highly effective method of assessing relative ceramic performance. This type of testing is highly efficient in terms of materials use and time. In other words, the DOP testing is an expedient screening test to determine which materials are worthy of a more extensive evaluation.

One must be cautious in comparing different sets of data from DOP, because they may vary with the specific method and materials used in the assembly of samples for ballistic testing. The data must be taken into account only as a comparative ranking rather than combined for a more global evaluation of the armour ceramics on the market today.

In order to compare the results obtained in DOP tests, several formulae were proposed by several authors. Darin Ray suggested a mass efficiency $(\mathrm{Em})$ based comparison using the following equation:

$$
\begin{aligned}
E_{m}= & \frac{\rho_{b a c} P_{b a c}}{\rho_{c \in r} t_{c e r}+\rho_{b a c} \text { DOP }} \\
\text { where: } & E m=\text { the mass efficiency } \\
& \rho_{b a c}=\text { the density of the backing material } \\
& \rho_{c c} r=\text { the density of the ceramic } \\
& P_{b a c}=\text { the penetration depth into the unprotected backing material } \\
& t_{c e r}=\text { the thickness of the ceramic target } \\
& D O P=\text { depth of penetration into backing after striking the ceramic target }
\end{aligned}
$$

In the above equation, the mass efficiency increases with decreasing DOP for a given set of materials and ceramic thickness, until the ceramic completely defeats the projectile. At the same time, increasing the thickness of the ceramic target increases the areal density and decreases the efficiency.

A variation of the equation (1) for calculating the ballistic performance of a ceramic in following DOP tests is suggested by Darin Ray. He used a formula to determine an equivalent thickness or thickness efficiency $\left(\mathrm{E}_{\mathrm{eq}}\right)$, another formula to obtain an equivalent mass or mass efficiency $\left(\mathrm{M}_{\mathrm{eq}}\right)$ and then, by combining them, they determine a quality factor or ballistic efficiency factor $\left(\mathrm{q}^{2}\right)$.

These formulae are:

$$
\begin{aligned}
E_{e q}= & \frac{P_{b a c}-P_{r e s}}{T_{c e r}} \\
M_{e q}= & \frac{P_{b a r}-P_{r s}}{T_{c a r}} \times \frac{P_{b a r}}{P_{a r r}}=E_{e q} \times \frac{P_{b a r}}{P_{a r r}} \\
q^{2}= & M_{e q} \times E_{e q} \\
& \text { where: } \\
& \mathrm{E}_{\mathrm{eq}}=\text { the equivalent thickness or thickness efficiency }
\end{aligned}
$$




\section{ACTA UIVERSITATIS CIBINIENSIS - TECHNICAL SERIES}

Vol. LXIX 2017

$\mathrm{Pbac}=$ the projectile penetration in the semi infinite backing

$\mathrm{P}_{\mathrm{res}}=$ the residual penetration of the projectile in the backing after penetrating the ceramic tile

$\mathrm{T}_{\mathrm{cer}}=$ the ceramic thickness

$\mathrm{M}_{\mathrm{eq}}=$ the equivalent mass or mass efficiency

$\rho_{\text {bac }}=$ the density of the acking

$\rho_{\text {cer }}=$ the density of the ceramic

$\mathrm{q}^{2}=$ quality factor or ballistic efficiency factor

The equivalent thickness or the thickness efficiency is defined as the thickness of the backing material, i.e., the PC replaced by one thickness unit of the ceramic material and the equivalent mass or the mass efficiency represents the mass of the backing material, replaced by one mass unit of the ceramic material to obtain the same effect on the projectile.

It can be seen that $\mathrm{E}_{\mathrm{eq}}$ and $\mathrm{M}_{\mathrm{eq}}$ are dimensionless factors that compare the ballistic performance of the ceramic to the backing material. The values of $\mathrm{E}_{\mathrm{eq}}$ and $\mathrm{M}_{\mathrm{eq}}$ for the backing material are unity. A number higher than unity denotes better ballistic performance of a material when compared to the reference backing material.

According to some opinions, the armour quality factor, $\mathrm{q}^{2}$, is important to armour designers because it relates both the mass and thickness or space efficiencies, since both the weight of the armour and the space it takes up are critical factors in designing armours.

Another name for the mass efficiency $\mathrm{M}_{\mathrm{eq}}$ equation used in DOP testing has been suggested by Murat [5]. He names it ballistic efficiency $(\eta)$ of a ceramic tile:

$$
\eta=\frac{\rho_{b a c}\left(P_{b a c}-P_{\text {res }}\right)}{\rho_{c e r}-t_{c e r}}
$$

where:

$\eta=$ the ballistic efficiency of ceramic tiles

$\rho_{\text {bac }}=$ the density of the backing

$\rho_{\text {cer }}=$ the density of the ceramic

$\mathrm{t}_{\mathrm{cer}}=$ the ceramic thickness

$\left(\mathrm{P}_{\text {bac }}-\mathrm{P}_{\mathrm{res}}\right)=$ the reduction in backing thickness penetrated due to ceramic tile in place, i.e. the difference between the reference depth and the residual depth.

Usually, a linear decrease of the residual penetration is observed when the ceramic thickness increases resulting in a linear increase of the mass efficiency Em with increased values of $\mathrm{T}_{\text {cer }}$. From such plots, a linear extrapolation of Em to a ceramic thickness which would stop the projectile just at the ceramic-backing interface (named critical thickness) defines the maximum mass efficiency Em,max as a characteristic material parameter. In one of his articles, Philips recommended a direct formula for calculating the critical thickness $\left(\mathrm{t}_{\text {crit }}\right)$ of a ceramic to just defeat the projectile, in a DOP test setting as:

$$
t_{\text {crit }}=\frac{t_{c e r} x P_{b a c}}{P_{b a c}-P_{\text {res }}}
$$

where:

$\mathrm{t}_{\text {crit }}=$ the critical thickness of the ceramic

$\mathrm{P}_{\mathrm{bac}}=$ the DOP in the backing material only

$\mathrm{t}_{\mathrm{cer}}=$ the thickness of the ceramic tile tested

$\mathrm{P}_{\mathrm{res}}=$ the residual DOP when the ceramic tile is used. 


\section{Conclusions}

The above equations (equations 1 to 6 ) constitute the basic set of tools for evaluating the ceramics during DOP tests. They provide enough information to the researcher in order to choose the ceramics worth being kept in the competition for a more in-depth research. The DOP test is considered the test of choice in screening ceramics due to its relevance, low costs, simplicity of the test and convenient data analysis. The advantage of this method is that it is relatively cheap to establish performance criteria for the armour tile however its disadvantage is that the semi-infinite backing is not representative for ballistic equipment and therefore its value is in assessing comparative tile performance.

At the same time, we have noticed that very good review of this matter and various approaches are provided by Normandia and Gooch [2] and Walley [6].

Overall, the ceramic armour production is increasing due to growing demand driven by the new conflicts involving developed nations all over the world. At the same time, evaluation of ceramic materials is of paramount importance since the lives of the military personnel depend on the functionality and reliability of their protection.

\section{References}

[1] J.C. Philips, A concise introduction to ceramics, Van Nostrand Reinhold, 1991.

[2] Normandia M.J.,Gooch W.A., An Overview of Ballistic Testing Methods of Ceramic Materials, Proceedings of the Ceramic Armour Materials by Design Symposium, Hawaii 2001.

[3] Darin Ray, Effect of Room Temperature Hardness and Tougness on the Ballistic Performances of SiC Based Ceramics, International Conference of the American Ceramic Society, 2005.

[4] Robertson C., Resistance of Different Ceramic Materials to Penetration by a Tungsten Carbide Core Projectile, Armor System Symposium, Tennessee, USA 2005.

[5] Murat Vural, Ballistic Performance of Alumina Ceramic Armors, Proceedings of the Ceramic Armour Materials by Design Symposium, Hawaii 2001.

[6] S.M. Walley. Historical review of high strain rate and shock properties of ceramics relevant to their application in armour. Advances in Applied Ceramics DOI 10.1179/174367609X422180. 